Revista de Educação e Pesquisa em Contabilidade Journal of Education and Research in Accounting Revista de Educación e Investigatión en Contabilidad
REPeC, Brasília, v. 6, n. 4, art. 2, p. 367-382, out./dez. 2012 Disponível online em www.repec.org.br

ISSN 1981-8610

\title{
Impacto do Processo de Convergência às Normas Internacionais de Contabilidade na Relevância das Informações Contábeis
}

\author{
Marcelo Alvaro da Silva Macedo \\ Doutor em Engenharia de Produção (COPPE/UFRJ) com Pós-Doutorado em Controladoria e Contabilidade (FEA-USP) \\ Professor do Programa de Pós-Graduação em Ciências Contábeis da Faculdade de Administração e Ciências Contábeis \\ da Universidade Federal do Rio de Janeiro \\ Av. Pasteur, 250 - LEDO/FACC/UFRJ - sala 250 - Urca - Rio de Janeiro - RJ - 22290-902 \\ E-mail: malvaro.facc.ufrj@gmail.com
}

\section{Marcelo Bicalho Viturino de Araújo}

Mestre em Controladoria e Contabilidade (FEA-USP)

Professor Susbstituto da Universidade Federal de Minas Gerais e Analista do Banco Central do Brasil

Av. Álvares Cabral, $1.605-2^{\circ}$ andar, Santo Agostinho, CEP: 30170-001, Belo Horizonte (MG)

E-mail: bicalho.araujo@bcb.gov.br

\section{Josué Pires Braga}

Doutorando em Controladoria e Contabilidade (FEA-USP)

Av. Prof. Luciano Gualberto, 908, FEA 3, Sala 16, Cidade Universitária, CEP: 05508-010 - São Paulo (SP)

E-mail: josuebraga@gmail.com

\section{Resumo}

A Lei n. ${ }^{\circ}$ 11.638/07 foi o marco inicial de uma série de mudanças na legislação que rege as práticas contábeis brasileiras. A principal razão para essas mudanças é o processo de convergência dos padrões contábeis locais para os internacionais. Com a Lei n. ${ }^{\circ} 11.638 / 07$, o precedente legal necessário para a consecução dessa convergência dos padrões contábeis foi estabelecido. Nesse contexto, o presente estudo tem como objetivo analisar o impacto do processo de convergência às normas internacionais de contabilidade na relevância das informações contábeis, tendo como base os dados de 2007 sem e com as alterações introduzidas pela Lei n. ${ }^{\circ}$ 11.638/07 e pelos Pronunciamentos do CPC, aplicáveis ao exercício de 2008 em diante. Para tanto, utiliza-se um estudo de value relevance, aplicando-se a análise de regressão às informações anuais de preço das ações (variável dependente) e lucro líquido por ação (LLPA) e patrimônio líquido por ação (PLPA) como variáveis independentes. Os principais resultados mostram que as informações contábeis de LLPA e PLPA do exercício de 2007, sem e com as alterações da legislação, apresentam-se relevantes para o mercado de capitais. Porém, uma comparação entre as duas regressões, utilizadas na análise, mostra que houve um ganho informacional para as informações contábeis com as alterações introduzidas pela primeira fase do processo de convergências contábil às normas internacionais.

Palavras-Chaves: Relevância da Informação Contábil; Convergências às Normas Internacionais de Contabilidade; Lei n. ${ }^{\circ}$ 11.638/07; Pronunciamentos do CPC.

\section{Editado em Português, Inglês e Espanhol. Versão original em Português.}

Recebido em 06/12/2011. Pedido de Revisão em 24/04/2012. Resubmetido em 18/06/2012. Aceito em 27/06/2012 por Valcemiro Nossa (Editor). Publicado em 30/11/2012. Organização responsável pelo periódico: CFC/FBC/ABRACICON.

Copyright (C) 2012 REPEC. Todos os direitos, até mesmo de tradução, são reservados. É permitido citar parte de artigos sem autorização prévia, desde que seja identificada a fonte. 


\section{repec}

\section{INTRODUÇÃO}

A adoção do IFRS no Brasil, em virtude do processo de convergência internacional dos padrões contábeis, ocorreu com alterações no marco regulatório da contabilidade financeira por meio da promulgação da Lei n. ${ }^{\circ}$ 11.638/07 (BRASIL, 2007) e Pronunciamentos emitidos pelo Comitê de Pronunciamentos Contábeis. Em consequência da promulgação, a Lei n. ${ }^{\circ} 6.404 / 76$ (BRASIL, 1976) determina que as normas expedidas pela Comissão de Valores Mobiliários (CVM) devem ser elaboradas em consonância com os padrões internacionais de contabilidade.

Nesse ambiente de mudanças, é importante para contadores, órgãos reguladores e investidores em geral ter conhecimento se a adoção do IFRS tem efeito sobre a informação disponibilizada. Além disso, é importante adicionar a literatura que investiga impactos da adoção do IFRS em diferentes contextos (países e culturas), se a alteração da forma de reconhecimento e mensuração pode acarretar alterações na associação entre preços de ativos e informações financeiras e, por conseguinte, na relevância dessas informações para o mercado de capitais. Isso porque, desde os primeiros estudos de Ball e Brown (1968) e Beaver (1968), a discussão de quais fatores contribuem ou reduzem a relevância das informações contábeis são essenciais para a normatização das práticas contábeis.

Nesse contexto, este estudo tem como objetivo analisar o impacto do processo de convergência às normas internacionais de contabilidade na relevância das informações contábeis, tendo como base os dados de 2007 sem e com as alterações introduzidas pela Lei n. ${ }^{\circ}$ 11.638/07 (BRASIL, 2007) e pelos Pronunciamentos do CPC, aplicáveis ao exercício de 2008 em diante.

Tem-se, então, como problema de pesquisa a seguinte pergunta: Qual o impacto da Lei n. ${ }^{\circ}$ 11.638/07 (BRASIL, 2007) e dos Pronunciamentos do CPC, aplicáveis ao exercício de 2008 em diante, na relevância das informações contábeis?

Justifica-se a utilização das informações do ano de 2007, pois algumas empresas reapresentaram as demonstrações de 2007, quando da apresentação das informações de 2008, com os ajustes preconizados pela Lei n. ${ }^{\circ}$ 11.638/07 (BRASIL, 2007) e pelos Pronunciamentos do CPC, aplicáveis ao exercício de 2008 em diante. Sendo assim, de maneira geral, a única diferença entre as informações apresentadas no início de 2008 e aquelas reapresentadas no início de 2009 é causada pelo processo de convergência às normas internacionais de contabilidade. Logo, consegue-se estabelecer uma análise satisfatória da relação causa-efeito, já que praticamente todas as outras influências estariam controladas, justificando-se qualquer alteração única e exclusivamente às mudanças introduzidas pela nova legislação. Cabe ressaltar, portanto, que, para nenhum dos outros períodos posteriores, é possível isolar esse efeito com tanta qualidade.

Ressalta-se que a relevância de estudos dessa natureza está em mostrar aos usuários da contabilidade o quanto as mudanças oriundas do processo de convergência às normas internacionais de contabilidade realmente impactam as informações contábeis, gerando com isso elementos e subsídios para que possam reconhecer esses impactos em seus processos de decisão a partir das demonstrações contábeis.

\section{O PROCESSO DE CONVERGÊNCIA CONTÁBIL NO BRASIL}

De acordo com Iudícibus, Martins e Gelbcke (2009), as mudanças mais relevantes em virtude do processo de internacionalização dos padrões contábeis são a primazia da essência sobre a forma. Tal característica pode ser caracterizada por situações nas quais as práticas contábeis se orientam por princípios e pelo objetivo de divulgar a essência econômica das transações. Nesse aspecto, a transição não é fácil, pois é necessária a capacidade analítica e de julgamento por parte dos profissionais da Contabilidade.

Esses pontos não são explícitos nas leis que estão promovendo a mudança no marco regulatório da Contabilidade brasileira, mas, ao se considerar a natureza das normas que estão sendo adotadas, tem-se que essa mudança de filosofia deve permear todo processo de convergência dos padrões contábeis. 
No caso do presente estudo, são analisadas as mudanças com vigência para o exercício de 2008, tendo em vista o objetivo de comparar a relevância das informações das demonstrações contábeis do exercício de 2007 sem alterações dos padrões e com alterações dos padrões. Muitas companhias adaptaram, em 2009, as demonstrações financeiras de 2007 publicadas em 2008 para fins comparativos, possibilitando essa comparação.

Serão abordados, então, aspectos relacionados ao reconhecimento e à mensuração dos elementos das demonstrações contábeis que sofreram alterações e que podem influenciar a qualidade da informação sobre o período analisado de 2007.

A Lei n. ${ }^{\circ}$ 6.385/76 ((BRASIL, 1976)) também é alterada pela Lei n. ${ }^{\circ}$ 11.638/07 (BRASIL, 2007) no processo de convergência dos padrões contábeis. Nesse caso, foi incluída a possibilidade de órgão e agências reguladoras, tais como CVM e Banco Central do Brasil, celebrarem convênios com entidade que tenha por objeto o estudo e a divulgação de princípios, normas e padrões de contabilidade e de auditoria.

A entidade referenciada acima é representada pelo Comitê de Pronunciamentos Contábeis (CPC), instituído pela Resolução CFC 1.055/05 (CFC, 2005). Com vigência a partir do exercício de 2008, o CPC emitiu um pronunciamento conceitual e 14 pronunciamentos técnicos aprovados pelas deliberações da CVM, os quais definem a vigência dos pronunciamentos. Os pronunciamentos emitidos até 2008 e as deliberações da CVM que os aprovaram são apresentados no Quadro 1. Cabe ressaltar, que o único CPC que não entrou em vigor em 2008 foi o CPC 11, que teve sua data de entrada em vigor apenas em 2010.

\begin{tabular}{|l|c|}
\multicolumn{1}{|c|}{ Pronunciamento Téenico } & Deliberação CVM \\
\hline Pronunciamento Conceitual Básico & $539 / 08$ \\
\hline CPC 01 - Redução ao valor recuperável de ativos & $527 / 07$ \\
\hline CPC 02 - Efeitos das mudanças nas taxas de câmbio e conversão de demonstrações contábeis. & $534 / 08$ \\
\hline CPC 03 - Demonstração dos Fluxos de Caixa & $547 / 08$ \\
\hline CPC 04 - Ativos Intangível & $553 / 08$ \\
\hline CPC 05 - Divulgação sobre partes relacionadas & $560 / 08$ \\
\hline CPC 06 - Operações de arrendamento mercantil & $554 / 08$ \\
\hline CPC 07 - Subvenção e assistência governamentais & $555 / 08$ \\
\hline CPC 08 - Custos de Transação e prêmios na emissão de títulos e valores mobiliários & $556 / 08$ \\
\hline CPC 09 - Demonstração do valor adicionado & $557 / 08$ \\
\hline CPC 10 - Pagamento baseado em ações & $562 / 08$ \\
\hline CPC 11 - Contratos de Seguro & $563 / 08$ \\
\hline CPC 12 - Ajuste a valor presente & $564 / 08$ \\
\hline CPC 13 - Adoção Inicial da Lei n. ${ }^{0}$ 11.638/07 e da MP 449/08 & $565 / 08$ \\
\hline CPC 14 - Instrumentos financeiros: reconhecimento, mensuração e evidenciação & $566 / 08^{(1)}$ \\
\hline
\end{tabular}

(1) Revogada pela Deliberação CVM 604, de 19 de novembro de 2009

Quadro 1: Pronunciamentos emitidos até 2008

Fonte: Pronunciamentos do CPC e Braga et al. (2010)

Vale destacar que o CPC 13 desobrigou as entidades da reapresentação das demonstrações contábeis referentes ao exercício de 2007 para fins comparativos, com duas alternativas de transição para as novas práticas contábeis:

- $\quad$ Abertura em $1^{\circ}$ de janeiro de 2008 ou encerramento em 31 de dezembro de 2007; e/ou

- Opção por reapresentar demonstrações contábeis comparativas, com abertura em $1^{\circ}$ de janeiro de 2007 ou encerramento em 31 de dezembro de 2006. 
No segundo caso, as alterações promovidas pela Lei n. ${ }^{\circ}$ 11.638/07 e pronunciamentos do CPC deveriam ser implementadas a partir de $1^{\circ}$ de janeiro de 2007, considerando seus efeitos na mensuração e divulgação contábil para o exercício de 2007. Podem ser destacados aspectos que sofreram alterações em critérios de reconhecimento e mensuração:

a) mensuração de instrumentos financeiros;

b) avaliação de investimentos societários;

c) reconhecimento de itens no ativo imobilizado;

d) reconhecimento de itens no ativo intangível;

e) não reconhecimento de itens no ativo diferido;

f) reconhecimento do prêmio na emissão de debêntures como receita;

g) reconhecimento dos gastos com emissão de ações no patrimônio líquido;

h) reconhecimento das doações e subvenções governamentais como receita;

i) impossibilidade da reavaliação de itens do ativo imobilizado; e

j) ajuste a valor presente dos elementos do ativo e do passivo exigível de longo prazo.

As alterações de critérios de reconhecimento e mensuração são discutidas e analisadas sinteticamente no Quadro 2, tendo por base as disposições das n. ${ }^{\text {os }} 6.404 / 76$ e 11.638/07 e dos Pronunciamentos do CPC obrigatórias para o exercício 2008 e facultativas para o exercício 2007:

\begin{tabular}{|c|c|}
\hline $\begin{array}{l}\text { Mensuração de } \\
\text { instrumentos } \\
\text { financeiros }\end{array}$ & $\begin{array}{l}\text { Investimentos mantidos até o vencimento: mensurados pelo valor original acrescido dos } \\
\text { rendimentos. Ativos e passivos financeiros destinados à negociação: mensurados pelo valor justo, } \\
\text { sendo as variações reconhecidas no resultado do período. Ativos financeiros disponíveis para venda: } \\
\text { mensurados pelo valor justo, sendo as variações reconhecidas no patrimônio líquido (ajustes de } \\
\text { avaliação patrimonial). Componentes das demonstrações contábeis potencialmente afetados pelas } \\
\text { alterações sofridas neste ponto: investimentos (ativo circulante ou não circulante); patrimônio } \\
\text { líquido; receitas ou despesas financeiras. }\end{array}$ \\
\hline $\begin{array}{l}\text { Aval } \\
\text { inves } \\
\text { socie }\end{array}$ & $\begin{array}{l}\text { Houve mudança na definição de coligada. O alcance da aplicação do método da equivalência } \\
\text { patrimonial foi estendido. A partir dessas alterações, podem existir investimentos que eram avaliados } \\
\text { pelo método do custo que passaram a ser avaliados pelo método da equivalência e vice-versa. } \\
\text { As variações cambiais decorrentes de investimentos no exterior devem ser registradas em conta } \\
\text { específica do patrimônio líquido. Componentes das demonstrações contábeis potencialmente } \\
\text { afetados pelas alterações sofridas neste ponto: investimentos (ativo não circulante); resultado de } \\
\text { equivalência patrimonial; patrimônio líquido. }\end{array}$ \\
\hline $\begin{array}{l}\text { imento } \\
\text { ativo } \\
\text { lo }\end{array}$ & $\begin{array}{l}\text { Com as alterações ocorridas, itens não corpóreos que possivelmente estejam no imobilizado devem } \\
\text { ser lançados no intangível. Além disso, operações de arrendamento mercantil financeiro devem } \\
\text { passar a ser reconhecidas como ativo, pois envolvem a transferência de benefícios, riscos e controle. } \\
\text { Deve ser analisado se o valor contábil do imobilizado (e de qualquer outro ativo) contém parcela } \\
\text { não recuperável. Os critérios utilizados para determinação da vida útil econômica estimada e para } \\
\text { cálculo da depreciação devem ser revisados e ajustados. Componentes das demonstrações contábeis } \\
\text { potencialmente afetados pelas alterações sofridas neste ponto: imobilizado (ativo não circulante); } \\
\text { despesa de depreciação; despesa financeira (pela mudança no tratamento do arrendamento } \\
\text { mercantil); reservas de lucros (por conta dos ajustes de exercícios anteriores). }\end{array}$ \\
\hline $\begin{array}{l}\text { Reconhecimento } \\
\text { de itens no ativo } \\
\text { intangível }\end{array}$ & $\begin{array}{l}\text { Com as mudanças, itens não corpóreos que possivelmente estejam em outro grupo (imobilizado ou } \\
\text { diferido) e que atendam a certos critérios devem ser registrados no ativo intangível. Componentes } \\
\text { das demonstrações contábeis potencialmente afetados pelas alterações sofridas neste ponto: } \\
\text { intangível (ativo não circulante). }\end{array}$ \\
\hline $\begin{array}{l}\text { Não } \\
\text { reconhecimento } \\
\text { de itens no ativo } \\
\text { diferido }\end{array}$ & $\begin{array}{l}\text { Esse grupo de contas foi extinto com a MP 449/08. Os saldos existentes devem ser reclassificados } \\
\text { (se possível), baixados contra lucros ou prejuízos acumulados ou mantidos até serem totalmente } \\
\text { amortizados. Componentes das demonstrações contábeis potencialmente afetados pelas alterações } \\
\text { sofridas neste ponto: diferido (ativo não circulante); reservas de lucros (por conta dos ajustes de } \\
\text { exercícios anteriores). }\end{array}$ \\
\hline
\end{tabular}




\begin{tabular}{|c|c|}
\hline $\begin{array}{l}\text { Reconhecimento } \\
\text { do prêmio na } \\
\text { emissão de } \\
\text { debêntures como } \\
\text { receita }\end{array}$ & $\begin{array}{l}\text { Esse item deixa de ser reconhecido diretamente no patrimônio líquido como reserva de capital e } \\
\text { passa a ser considerado como receita, sendo apropriado ao resultado de acordo com os prazos da } \\
\text { dívida. Componentes das demonstrações contábeis potencialmente afetados pelas alterações sofridas } \\
\text { neste ponto: receitas ou despesas financeiras. }\end{array}$ \\
\hline $\begin{array}{l}\text { Reconhecimento } \\
\text { dos gastos com } \\
\text { emissão de ações } \\
\text { no patrimônio } \\
\text { líquido }\end{array}$ & $\begin{array}{l}\text { Esse item deixa de ser reconhecido diretamente no resultado do período e passa a ser lançado como } \\
\text { conta retificadora do grupo capital social no patrimônio líquido. Componentes das demonstraços } \\
\text { contábeis potencialmente afetados pelas alterações sofridas neste ponto: patrimônio líquido; } \\
\text { resultado do período (pelo estorno dos gastos com emissão de ações). }\end{array}$ \\
\hline $\begin{array}{l}\text { Reconhecimento } \\
\text { das doações } \\
\text { e subvenções } \\
\text { governamentais } \\
\text { como receita }\end{array}$ & $\begin{array}{l}\text { Esse item deixa de ser reconhecido diretamente no patrimônio líquido como reserva de capital } \\
\text { e passa a ser considerado como receita, sendo apropriado ao resultado à medida que atender aos } \\
\text { critérios de reconhecimento. Componentes das demonstrações contábeis potencialmente afetados } \\
\text { pelas alterações sofridas neste ponto: receita de doações e subvenções (ou de incentivos fiscais); } \\
\text { patrimônio líquido. }\end{array}$ \\
\hline $\begin{array}{l}\text { Impossibilidade } \\
\text { da reavaliação } \\
\text { de itens do ativo } \\
\text { imobilizado }\end{array}$ & $\begin{array}{l}\text { O dispositivo legal que possibilitava a reavaliação de elementos do ativo foi revogado. Os saldos } \\
\text { existentes na reserva de reavaliação poderiam ser mantidos até sua efetiva realização ou estornados } \\
\text { até o final do exercício social em que a Lei n. }{ }^{\circ} 11.638 / 07 \text { entrasse em vigor. Componentes das } \\
\text { demonstrações contábeis potencialmente afetados pelas alterações sofridas neste ponto: imobilizado } \\
\text { (ativo não circulante); patrimônio líquido. }\end{array}$ \\
\hline $\begin{array}{l}\text { Ajuste a valor } \\
\text { presente dos } \\
\text { elementos } \\
\text { do ativo e do } \\
\text { passivo exigível } \\
\text { de longo prazo }\end{array}$ & $\begin{array}{l}\text { Com as alterações, os elementos do ativo decorrentes de operações de longo prazo e as obrigações, } \\
\text { encargos e riscos classificados no passivo exigível a longo prazo serão ajustados a valor presente, } \\
\text { sendo os demais ajustados quando houver efeito relevante. Componentes das demonstrações } \\
\text { contábeis potencialmente afetados pelas alterações sofridas neste ponto: realizável a longo prazo } \\
\text { (ativo não circulante); passivo exigível (não circulante); receitas ou despesas financeiras. }\end{array}$ \\
\hline
\end{tabular}

Quadro 2: Aspectos com alterações de critérios na mensuração e reconhecimento contábil

Fonte: Lei n. ${ }^{\circ}$ 6.404/76, Lei n. ${ }^{\circ}$ 11.638/07, Pronunciamentos do CPC e Braga et al. (2010)

Importantes alterações relativas à mensuração e ao reconhecimento dos elementos das demonstrações contábeis foram relatadas acima. Porém, vale ressaltar que ocorreram outras alterações além de aspectos de mensuração e reconhecimento, como, por exemplo, a adoção da Demonstração do Valor Adicionado (DVA) pelas companhias abertas. Porém, foram focados os aspectos anteriormente citados, pois são aqueles que podem influenciar valores contábeis que serão aplicados no modelo de análise do presente estudo. Ressalta-se, por fim, que outras alterações foram introduzidas após 2008, com a emissão de novos CPCs.

\section{VALUE RELEVANCE: A RELEVÂNCIA DA INFORMAÇÃO CONTÁBIL}

Kothari (2001), em levantamento bibliográfico sobre pesquisas relacionadas ao mercado de capitais, destaca como principais precursores em pesquisas sobre relevância da informação contábil: Ball e Brown (1968) e Beaver (1968).

Ball e Brown (1968) relacionaram componentes contábeis com o valor de mercado das empresas. Esses autores pesquisaram a relação dos lucros contábeis anormais e o valor das ações, com evidências de que o anúncio de lucro tem valor informativo para o mercado, com ajuste gradual dos retornos anormais. Tal fato traz indícios de que nem toda informação é completamente antecipada pelo mercado.

Já Beaver (1968) pesquisou o conteúdo informativo de componentes da contabilidade, tais como o lucro, avaliando a reação do mercado à divulgação contábil e também à volatilidade dos retornos anormais. Os resultados mostraram que o mercado, mas, especificamente, a volatilidade dos preços reage à divulgação das informações contábeis.

As pesquisas sobre relevância das informações contábeis têm, em geral, objetivo de avaliar sua relação com valores de mercado. A visão inicial restringiu-se a avaliar como os valores contábeis 
relacionam-se com o comportamento das ações. Ball e Brown (1968), nessa abordagem inicial, desenvolveram técnicas de mensuração de impacto da informação contábil.

Holthausen e Watts (2001) definem como Value Relevance Literature os estudos empíricos que investigam a relação entre os valores de mercado (ou suas alterações) e valores contábeis e que tenham a finalidade de avaliar e fornecer melhor base de avaliação desses números e/ou efeitos de normas contábeis. Esses autores ainda comentam que os relatórios financeiros servem a múltiplas funções, incluindo aquelas não relacionadas ao valor da empresa (non-valuation functions), que têm importantes implicações nos relatórios financeiros.

Holthausen e Watts (2001) criticam o fato de pesquisas de value relevance não servirem como os subsídios necessários às decisões de órgãos reguladores de normas contábeis. Entretanto, Barth, Beaver e Landsman (2001) consideram que a pesquisa não está condicionada a esse intuito, já que os investidores não são os únicos usuários da informação.

Em ambos os estudos, fica claro que o objetivo deste tipo de pesquisa é prover evidências sobre como componentes contábeis se relacionam com preços de ações (valor de mercado das empresas).

Holthausen e Watts (2001) classificam os estudos de value relevance em três categorias, sendo que um mesmo estudo pode estar em mais de uma categoria:

i) Relative association studies, que comparam a associação entre os valores do mercado de ações (ou alterações desses valores) com formas de mensuração alternativas, tais como um padrão contábil existente e um a ser proposto. Esses estudos realizam normalmente a comparação dos $R^{2}$ dos modelos de regressão, sendo que o padrão contábil com maior $R^{2}$ é avaliado como mais relevante;

ii) Incremental association studies, que investigam se o componente contábil em análise é útil para explicar valores ou retornos ao longo de períodos de tempo, sendo importante incluir outras variáveis. Considera-se um valor relevante se o seu coeficiente de regressão estimado é significativamente diferente de zero; e

iii) Marginal information content studies, que investigam se determinado valor adiciona poder informacional aos investidores em relação às informações disponíveis. Tipicamente são utilizadas metodologias de estudos de evento, onde o interesse é avaliar de a disponibilidade de determinada informação está associada a alterações de valor de ativos (reação de preços), onde reações são consideradas evidências da relevância.

Segundo Barth, Beaver e Landsman (2001), os estudos de value relevance possuem objetivos específicos e hipóteses alternativas sobre relevância e confiabilidade de números contábeis. Podem existir diferentes formas de avaliação, mas tipicamente utilizam valores de mercado das empresas (ações). Os testes procuram avaliar os coeficientes sobre os valores contábeis utilizados e que tenham sido estimados em modelos de regressão. Alguns tipos de estudos são citados pelos autores:

i) Avaliação dos coeficientes específicos de componentes contábeis onde a rejeição da hipótese nula traz evidências de que os valores dos coeficientes são significantes.

ii) Avaliação se os coeficientes de valores contábeis reconhecidos são diferentes de outros valores que poderiam ser também reconhecidos nos relatórios financeiros em diferente prática contábil. A rejeição da hipótese nula traz evidência de que diferenças na forma de reconhecimento são relevantes.

iii) Avaliação se os coeficientes de valores contábeis deferem de seu coeficiente teórico dos modelos de avaliação, onde a rejeição da hipótese nula traz evidências de falha das características propostas pelo modelo às variáveis utilizadas para mensuração.

Diante das classificações e definições abordadas, basicamente, podem ser destacados três objetivos dos estudos de value relevance: i) testar a relevância das informações contábeis em relação aos preços das ações; ii) testar relevância de informações contábeis específicas, que podem servir de subsídios à decisão de investidores; e iii) sugerir e contribuir no desenvolvimento de modelos de avaliação e acompanhamento. 
De acordo com Holthausen e Watts (2001), as teorias subjacentes aos estudos de value relevance, normalmente assumem duas configurações: i) direct valuation theory e ii) inputs-to-equity-valuation theory. No primeiro caso, avalia-se o lucro contábil ou o patrimônio líquido como mensuração do valor de mercado das ações e suas alterações, onde a medida contábil teria forte associação com a mensuração das ações. Na segunda configuração, a ideia é prover informações para serem utilizadas em modelos de avaliação de empresas utilizados por investidores, cujas associações entre valores contábeis e o valor de mercado de ações de empresas são esperados, mas apenas de forma incremental.

Holthausen e Watts (2001) destacam que a maioria das pesquisas de value-relevance não tem o intuito de questionar se o valor contábil do patrimônio ou do lucro devem ser uma estimativa do valor de mercado, mas se existe relação significativa entre essas informações contábeis e o preço das ações da empresa no mercado de capitais.

O foco deste estudo, na classificação dada por Holthausen e Watts (2001), pode ser tipificado como relative association studies. Importantes contribuições podem ser listadas nesse tipo de estudo.

Harris, Lang e Moller (1994) compararam a relevância de informações contábeis reconhecidas e mensuradas por empresas alemãs e americanas, tendo como contexto que o sistema contábil alemão foca a preservação do capital, a proteção de credores e a facilitação do processo de tributação. Foi analisada a associação de retornos de ação e ganhos contábeis em longos períodos, considerando dados anuais. O estudo indica que existe relevância dos ganhos contábeis de corporações alemãs, com maior poder explicativo de dados consolidados e com alteração não significativa quando do alinhamento com práticas americanas.

Dhaliwal, Subramanyam e Trezevant (1999) avaliaram a relevância relativa do resultado abrangente (comprehensive income) e do lucro líquido para explicar o desempenho do retorno de ações. Não foram encontradas evidências de maior associação do resultado abrangente com retorno e valor de ações ou maior capacidade de previsão de fluxos de caixa.

Amir, Harris e Venuti (1993), no contexto de empresas não americanas registradas no mercado de capitais americano que adaptam suas informações ao padrão americano, investigaram se as diferenças de informação eram significativas e se tinham efeitos na associação com os valores das ações dessas empresas. Os autores concluem que as reconciliações possuem relevância incremental às informações baseadas no padrão doméstico.

No Brasil, estudos foram realizados no intuito de analisar a relevância da informação contábil, tendo por base a relação entre os preços das ações e os componentes contábeis. O trabalho de Lopes (2001) é referência nesse tipo de pesquisa, com a utilização do Modelo de Ohlson na interpretação das informações contábeis.

\section{ESTUDOS DE VALUE RELEVANCE EM UM CONTEXTO DE DIFERENTES PRÁTICAS CONTÁBEIS OU DE CONVERGÊNCIA CONTÁBIL}

Niskaen, Kinnunen e Kasanen (2000), em pesquisa com empresas na Finlândia, indicaram que alterações nos lucros em virtude de transformação do padrão contábil doméstico para o previsto nas normas internacionais não trouxeram incremento significativo de relevância para a informação contábil.

Bartov, Goldberg e Kim (2005), utilizando dados de 417 empresas alemãs no padrão contábil alemão, US-GAAP e IFRS, entre os anos de 1998 a 2000, indicaram maior relevância das informações contábeis em US-GAAP e IFRS quando comparado com o padrão contábil alemão. Corroborando esses indícios, Hung e Subramanyam (2007) concluíram que o ativo total e o patrimônio líquido, bem como as variações no lucro e no patrimônio líquido, foram mais relevantes pelo padrão internacional do que aquele previsto no padrão alemão.

Costa e Lopes (2007) em pesquisa com empresas brasileiras com American Depositary Recepts (ADRs) analisaram as variáveis lucro líquido e patrimônio líquido para o período entre 1999 e 2003. Com utilização do modelo de Ohlson, foi concluído que: i) informações elaboradas segundo o padrão brasileiro são relevantes; ii) informações em US-GAAP disponibilizadas em junho possuem menor ou 


\section{repec}

igual relevância do que as divulgadas em abril; e iii) os ajustes aos US-GAAP efetuados no patrimônio líquido são relevantes para o mercado de capitais brasileiro.

Morais e Curto (2008), em estudo realizado em Portugal, concluíram sobre redução de relevância com a adoção das normas internacionais do IASB. Já Barth, Landsman e Lang (2008) trouxeram evidências com pesquisa, considerando empresas de 21 países, de que a adoção de normas internacionais melhorou a relevância das informações contábeis, quando comparada com a adoção de padrões locais.

Com a inclusão de previsões de analistas financeiros, Chalmers, Clinch e Godfrey (2008) avaliaram a ocorrência de alterações significativas na precisão das previsões antes e depois da adoção das normas internacionais. A pesquisa indica que a acurácia das precisões elevaram após a implantação dos padrões internacionais de contabilidade, com indícios de aumento do nível de informações para avaliação dos analistas.

Chalmers, Clinch e Godfrey (2009) investigaram alterações na relevância dos valores reportados sobre lucro e patrimônio para investidores, tendo como contexto a adoção gradual do IFRS em empresas australianas. A pesquisa teve por base o período de 1990 a 2007, onde a adoção do IFRS inicia em um momento intermediário do período. Os resultados indicam que valores de lucros das empresas australianas tornaram-se mais relevantes com a adoção do IFRS, mas o valor do patrimônio não alterou significativamente. Tal estudo sugere que mesmo para países com forte proteção aos investidores e com boa qualidade dos princípios contábeis, a adoção do IFRS pode interferir, significativamente, em associações entre as informações financeiras e o valor de mercado.

Morais e Curto (2009) concluíram que informações pelas normas internacionais (IAS/IFRS) eram mais relevantes do que as informações em padrões locais em países europeus, corroborando os resultados encontrados por Barth, Landsman e Lang (2008).

Na Malásia, Kadri, Aziz e Ibrahim (2009) demonstraram que a alteração de padrão contábil para o IFRS trouxe indícios de relevância da informação contábil, ao contrário de estudos anteriores à adoção das normas internacionais no país, que concluíam pela falta de relevância da informação contábil.

\section{METODOLOGIA}

Esta pesquisa pode ser caracterizada, de acordo com Vergara (2009), como um estudo descritivo e explicativo, pois procura expor características das informações contábeis (no caso sua relevância), no ano de 2007, por meio da análise da relação entre essas informações e o comportamento dos preços das ações. Quanto à abordagem utilizada, classifica-se, de acordo com Martins e Theóphilo (2009), como empírico-positivista, pois apresenta técnicas de coleta, tratamento e análise de dados marcadamente quantitativos e onde a validação da prova científica é buscada através de testes dos instrumentos, graus de significância e sistematização das definições operacionais.

A população-alvo da pesquisa é composta pelas companhias não financeiras de capital aberto listadas na Bolsa de Valores de São Paulo (Bovespa) que reapresentaram voluntariamente suas demonstrações de 2007 em 2009, contendo as alterações de critérios contábeis definidas pela Lei n. ${ }^{0} 11.638 / 07$ e pelos Pronunciamentos do CPC para fins comparativos. Dentre as que reapresentaram foram excluídas, então, as companhias do setor financeiro, seguradoras e companhias de participação (holdings). As demonstrações contábeis foram coletadas no site da Bovespa por meio do sistema Divulgação Externa (DivExt). No final, tem-se a população-alvo formada por 75 empresas. Porém, por conta da indisponibilidade de informações do mercado de ações a amostra final ficou composta por 55 empresas (mais de $70 \%$ da população-alvo), que fizeram parte da análise.

Foram coletadas das demonstrações financeiras as informações referentes ao Lucro Líquido (LL) e ao Patrimônio Líquido (PL) das empresas da amostra, em relação ao exercício de 2007. Adicionalmente, obtiveram-se informações referentes ao preço das ações e à quantidade de ações, obtidas da Economática ${ }^{\circledR}$.

Para o preço das ações, considerou-se o preço da ação de maior liquidez da empresa na data de 30 de abril de 2008. Para selecionar a ação de maior liquidez, consideraram-se três fatores simultaneamente 
(quantidade de negócios, quantidade de títulos negociados e volume monetário negociado), pois eles apontaram sempre para a mesma escolha. Em relação à quantidade de ações que foi utilizada para encontrar as informações de Lucro Líquido por ações (LLPA) e ao Patrimônio Líquido por ação (PLPA), foi considerada a data de 31/12/2007.

Como dito anteriormente, para a análise, foi considerado apenas o período de 2007, já que ele é o único em que se podem isolar os efeitos da Lei n. ${ }^{\circ} 11.638 / 07$ e dos Pronunciamentos do CPC, aplicáveis ao exercício de 2008 em diante. Apenas para o ano de 2007 tem-se a possibilidade de obter informações cuja diferença está somente nas alterações de critérios contábeis definidas nessa legislação.

As regressões (com dados antes e depois da primeira fase do processo de convergência às normas internacionais de contabilidade) que são feitas para a análise de value relevance consideram variáveis comumente encontradas em estudos dessa natureza, que visam analisar a relevância das informações contábeis num ambiente de mudança de normas. O modelo econométrico utilizado para mensurar a relação existente entre o preço das ações e as informações contábeis teve como base os trabalhos de Collins, Maydew e Weiss (1997) e Chalmers, Clinch e Godfrey (2009).

A análise está dividida, então, em duas partes, sendo cada uma relacionada a uma situação específica: sem e com as alterações previstas na legislação que regulou o processo de convergência contábil às normas internacionais. Para todas as análises, fez-se uso de regressões lineares múltiplas, tendo sempre o preço como variável dependente e as informações contábeis (LLPA e PLPA) combinadas como variáveis independentes.

Neste ponto, é importante destacar que a análise tem como foco a comparação dos dois conteúdos informacionais, no sentido de verificar qual das duas informações (sem e com as alterações previstas no processo de convergência às normas internacionais de contabilidade) está mais contida na formação dos preços. Nesse sentido, ressalta-se que se a informação com as alterações for mais relevante, isto pode indicar que o mercado já considerava informalmente tais mudanças na formação dos preços.

Para verificar a relevância das informações contábeis (value relevance), utilizou-se a seguinte equação:

$$
\mathrm{p}_{\mathrm{i}}=\alpha_{0}+\alpha_{1} L L P A_{i}+\alpha_{2} P L P A_{i}+\varepsilon_{i}
$$

Onde:

$\mathrm{p}_{\mathrm{i}}=$ Variável dependente, representada pelo preço da ação da empresa $i$;

$\alpha_{0}=$ Intercepto;

$\alpha_{1}=$ Coeficiente de inclinação para o LLPA;

$\alpha_{2}=$ Coeficiente de inclinação para o PLPA;

$\mathrm{LLPA}_{\mathrm{i}}=$ Variável independente, representada pela divisão do lucro líquido (LL) advindo da DRE pelo número de ações da empresa $i$;

$\mathrm{PLPA}_{\mathrm{i}}=$ Variável independente, representada pela divisão do patrimônio líquido (PL) advindo do BP pelo número de ações da empresa $i$;

$\varepsilon=$ Erro aleatório (ruído branco) com distribuição normal, média zero e variância constante.

A análise de regressão, de acordo com Corrar, Paulo e Dias Filho (2007), consiste basicamente em determinar uma função que descreva ou explique o comportamento da variável dependente com base nos valores de uma (regressão simples) ou mais (regressão múltipla) variáveis independentes. Para estimar essa função, complementa Gujarati (2006), podem-se utilizar diversos métodos, sendo o mais comum, que é utilizado no presente estudo, os Mínimos Quadrados Ordinários (MQO).

Porém, segundo Fávero et al. (2009), para aceitar-se a função estimada, faz-se necessário testar o coeficiente de determinação da regressão $\left(\mathrm{R}^{2}\right)$ e os coeficientes das variáveis independentes. Para testar o modelo como um todo, ressaltam Gujarati (2006) e Corrar, Paulo e Dias Filho (2007), faz-se um teste F, que 
tem como hipótese nula $\left(\mathrm{H}_{0}\right)$ que o $\mathrm{R}^{2}$ é igual a zero. Para que a regressão possa ser aceita, tem-se que rejeitar esta $\mathrm{H}_{0}$. Já para testar os coeficientes das variáveis independentes, complementam Gujarati (2006) e Corrar, Paulo e Dias Filho (2007), faz-se um teste $t$, que tem como hipótese nula $\left(\mathrm{H}_{0}\right)$ que os coeficientes são nulos (iguais a zero). Do mesmo modo que o teste anterior, para que uma variável possa ser incluída no modelo que descreve ou explica o comportamento da variável independente, tem-se que rejeitar esta $\mathrm{H}_{0}$. Em ambos os casos, o $p$-value do teste precisa ser inferior ao nível de significância, que para o presente estudo é de 1\%.

Além dos testes F e $t$, para se fazer uma análise de regressão, destacam Fávero et al. (2009), Corrar, Paulo e Dias Filho (2007) e Gujarati (2006), é necessário testar seus pressupostos, que são: normalidade dos resíduos, homocedasticidade dos resíduos, autocorrelação dos resíduos e multicolinearidade das variáveis independentes. Em outras palavras, para que um modelo de regressão seja aceito, é necessário que os resíduos sejam normalmente distribuídos, que sua variância seja constante e que eles não estejam correlacionados. Além disso, é necessário que as variáveis independentes (regressores) não sejam correlacionadas. Neste trabalho, os testes de todos os pressupostos foram feitos para todas as regressões. A seguir tem-se a descrição dos testes utilizados.

Para testar a normalidade, utilizou-se o teste de Jarque-Bera (JB), que, segundo Gujarati (2006), consiste em um teste da hipótese conjunta de assimetria $(S=0)$ e curtose $(K=3)$ da distribuição dos resíduos da regressão. Já para a homocedasticidade, utilizou-se o teste de Breusch-Pagan-Godfrey, que, de acordo com Gujarati (2006), consiste em testar a hipótese de que as variâncias dos erros (resíduos) são iguais. Para a multicolinearidade, foi utilizada estatística FIV (variance inflation factor), que, segundo Fávero et al. (2009), é uma medida de quanto a variância de cada coeficiente de regressão estimado aumenta devido à multicolinearidade. Para que a regressão seja aceitável, é necessário que o FIV seja menor que dez.

Por fim, para a autocorrelação, foi utilizado o teste de Durbin-Watson (DW), que, de acordo com Gujarati (2006), é o teste mais aplicado para detecção de autocorrelação dos resíduos. Cabe ressaltar que a estatística DW será apresentada meramente em caráter ilustrativo, pois, segundo Fávero et al. (2009), não faz sentido se falar em autocorrelação quando os dados estão em cross-section, como no caso da presente pesquisa.

Todos os testes, à exceção do FIV que foi rodado no SPSS 16.0, foram executados no Eviews 6.0, onde também foram feitas as análises de regressão. Ainda cabe salientar que, para os casos em que se encontrou problema de heterocedasticidade, foi utilizada a correção de Newey-West, que, segundo Gujarati (2006), corrige os erros-padrão dos coeficientes, tornando-os consistentes para heterocedasticidade.

A análise comparativa dos resultados das equações de regressão para os dados antes e depois das mudanças provenientes da primeira fase do processo de convergência às normas internacionais de contabilidade, para verificar o impacto dessas alterações no nível de relevância das informações contábeis, é feita primeiramente pela comparação entre os $\mathrm{R}^{2}$ ajustados. Desse modo, quanto maior o $\mathrm{R}^{2}$ maior será a contribuição das variáveis. Além disso, também, utilizaram-se os critérios de informação de Akaike (CIA) e de Schwarz (CIS), que, segundo Fávero et al. (2009), são utilizados para escolher entre modelos concorrentes. Tanto no caso do CIA quanto no CIS, o melhor modelo será aquele que apresentar os menores valores.

\section{ANÁLISE DOS RESULTADOS}

Com base na utilização dos softwares Eviews 6.0 e SPSS 16.0, obtiveram-se os resultados para as regressões apresentadas anteriormente, bem como para os testes necessários. Para todas as análises, considerou-se o nível de significância de 1\%. A Tabela 1 apresenta os resultados para a regressão, considerando os dados originais, ou seja, antes das mudanças. Já a Tabela 2 mostra os resultados da regressão para os dados reapresentados em 2009, voluntariamente.

Os resultados da Tabela 1 revelam um $\mathrm{R}^{2}$ ajustado, significativo a 1\%, de 0,6908, o que mostra que $69,08 \%$ da variação do preço é explicada pela variação do LLPA e do PLPA. Isso mostra, mesmo que 
preliminarmente, o poder de explicação do comportamento do preço das ações das empresas no mercado de capitais pelas variáveis LLPA e PLPA, sem considerar as alterações na legislação.

Tabela 1: Relevância do LLPA e do PLPA sem as alterações na legislação

\begin{tabular}{|c|c|c|c|c|}
\hline $\begin{array}{c}\text { Variável Explicativa } \\
\text { ou Independente }\end{array}$ & Coeficiente & Erro Padrão & $t$ & p-value \\
\hline LLPA & 4,2277 & 0,6826 & 6,1938 & 0,0000 \\
\hline PIPA & 0,5991 & 0,0984 & 6,0872 & 0,0000 \\
\hline $\mathrm{C}$ & 7,7166 & 1,8001 & 4,2853 & 0,0001 \\
\hline Infs. Adicionais & Valores & \multicolumn{2}{|c|}{ Infs. Adicionais } & Valores \\
\hline $\mathrm{R}^{2}$ & 0,7022 & \multicolumn{2}{|l|}{ F (estat.) } & 61,3120 \\
\hline $\mathrm{R}^{2}$ ajustado & 0,6908 & \multicolumn{2}{|l|}{$\mathrm{F}(p$-value $)$} & 0,0000 \\
\hline Jarque-Bera (estat.) & 2,0989 & \multicolumn{2}{|c|}{ Breusch-Pagan-Godfrey (estat. F) } & 19,3018 \\
\hline Jarque-Bera (p-value) & 0,3501 & \multicolumn{2}{|c|}{ Breusch-Pagan-Godfrey ( $p$-value) } & 0,0000 \\
\hline Durbin-Watson (DW) & 2,0875 & \multicolumn{2}{|l|}{ FIV (LLPA e PLPA) } & 44,8740 \\
\hline CIA & 7,7362 & \multicolumn{2}{|l|}{ CIS } & 7,8457 \\
\hline
\end{tabular}

Além disso, tem-se significância para ambas as variáveis independentes, pois os dois p-values do teste $t$ são menores que $1 \%$. Também, pode-se observar que a regressão não apresenta problemas de normalidade dos resíduos ( $p$-value do teste de Jarque-Bera $>1 \%$ ).

Porém, a regressão apresenta problemas de heterocedasticidade dos resíduos ao nível de $1 \%$. Isso quer dizer que não se aceita $\mathrm{H}_{0}$ de variância constante dos erros. Por conta desse problema de heterocedasticidade, os erros-padrão, bem como o valor do teste $t$ e seu $p$-value, já estão estimados com correção de Newey-West.

Portanto, pelos fatos expostos, pode-se afirmar que a informação contábil de LLPA e PLPA de 2007 é significativa para o mercado de capitais, quando analisados os dados antes das mudanças oriundas da primeira fase do processo de convergência às normas internacionais de contabilidade.

Pela análise da Tabela 2, percebe-se que a regressão do preço da ação contra o LLPA e o PLPA, considerando as informações reapresentadas com as alterações de critérios contábeis definidas pela Lei n. ${ }^{\circ} 11.638 / 07$ e Pronunciamentos do CPC, aplicáveis ao exercício 2008 em diante, tem um $\mathrm{R}^{2}$ ajustado de 0,7276 , que é significativo a $1 \%$ (p-value do teste $\mathrm{F}<0,01$ ). Isso significa que $72,76 \%$ da variação do preço é explicada pela variação do LLPA e do PLPA, mostrando o poder de explicação das variáveis LLPA e PLPA, considerando as mudanças na legislação.

Tabela 2: Relevância do LLPA e do PLPA com as alterações na legislação

\begin{tabular}{c|c|c|c|c}
\hline $\begin{array}{c}\text { Variável Explicativa } \\
\text { ou Independente }\end{array}$ & $\mathbf{0 , 7 2 7 6}$ & \multicolumn{1}{|c|}{ Erro Padrão } & $\boldsymbol{t}$ & $\boldsymbol{p}$-value \\
\hline LLPA & 3,9601 & 0,4859 & 8,1505 & 0,0000 \\
\hline PLPA & 0,5607 & 0,0700 & 8,0100 & 0,0000 \\
\hline C & 7,8893 & 1,3995 & 0,0000 \\
\hline Infs. Adicionais & Valores & \multicolumn{1}{|c}{ Infs. Adicionais } & Valores \\
\hline $\mathrm{R}^{2}$ & 0,7377 & F (estat.) & 73,1328 \\
\hline $\mathrm{R}^{2}$ ajustado & 0,7276 & F (p-value) & 0,0000 \\
\hline Jarque-Bera (estat.) & 1,4359 & Breusch-Pagan-Godfrey (estat. F) & 8,6842 \\
\hline Jarque-Bera (p-value) & 0,4878 & Breusch-Pagan-Godfrey (p-value) & 0,0006 \\
\hline Durbin-Watson (DW) & 2,2740 & FIV (LLPA e PLPA) & 37,6250 \\
\hline CIA & 7,6092 & CIS & 7,7187 \\
\hline
\end{tabular}




\section{repec}

Isso é complementado pela significância dos coeficientes de ambas as variáveis, que é apontado pelos $p$-values dos testes $t$, que possuem valores inferiores a $1 \%$. Pode-se observar que a regressão também não apresenta problemas de normalidade dos resíduos ( $p$-value do teste de Jarque-Bera $>1 \%$ ).

Porém, novamente a regressão apresentou problemas de heterocedasticidade dos resíduos, ao nível de 1\% ( $p$-value do teste de Breusch-Pagan-Godfrey $<1 \%)$. Assim sendo, como não se pode aceitar a $\mathrm{H}_{0}$ de que variância dos resíduos é constante, os erros-padrão, bem como o valor do teste $t$ e seu $p$-value, já estão estimados com correção de Newey-West.

Logo, pelos fatos expostos, pode-se afirmar que as informações contábeis de LLPA e PLPA de 2007 também são significativas para o mercado de capitais, mesmo quando analisados os dados depois das mudanças oriundas da primeira fase do processo de convergência às normas internacionais de contabilidade.

Pode-se observar que, no caso dessas duas regressões, tem-se FIV $>10$, o que geraria uma situação de multicolinearidade não aceitável. Porém, segundo Fávero et al. (2009), a alta colinearidade entre as variáveis independentes não gera, necessariamente, estimadores ruins ou fracos e sua presença não significa que o modelo possua problemas, contudo sua existência acaba gerando aumentos nos termos de erro.

Por isso, Corrar, Paulo e Dias Filho (2007) e Gujarati (2006) enfatizam que a principal característica de regressões com problemas de multicolinearidade é ter $\mathrm{R}^{2}$ alto, mas poucas variáveis significativas, exatamente pelo termo de erro ser muito grande. Em outras palavras, os erros dos coeficientes das variáveis independentes serão grandes e com isso eles terão problemas para se apresentarem significativos (diferentes de zero).

Cabe salientar que isso não acontece no caso deste trabalho, pois todos os coeficientes das variáveis independentes (LLPA e PLPA) são significativos em ambos os casos. Logo, apesar de o FIV apresentar-se alto, não se observa o impacto esperado da multicolinearidade na significância dos coeficientes das variáveis explicativas.

Ainda, segundo Gujarati (2006), mesmo que a multicolinearidade se apresente muito alta, como no caso das duas regressões feitas nesse trabalho, se os outros pressupostos (normalidade e homocedasticidade dos resíduos) forem atendidos ou corrigidos, os estimadores obtidos pelo MQO ainda terão as propriedades necessárias para serem os melhores estimadores lineares não tendenciosos.

Gujarati (2006) e Fávero et al. (2009) ressaltam que o problema de multicolinearidade pode estar na conjugação da relação teórica entre as variáveis (o que é naturalmente esperado para o caso desse artigo, pois é esperado que LL e PL estivessem fortemente relacionados) com a relação dos dados que estão sendo utilizados, causada pela amostragem utilizada. É possível perceber que, para o presente estudo corrigir esses problemas, se torna impraticável, visto que as variáveis que devem ser usadas são exatamente estas, pois o único período possível para a análise é o ano de 2007, e as empresas utilizadas são as que apresentaram voluntariamente as informações necessárias para o estudo.

Logo, apesar do problema de multicolinearidade apresentado pelo FIV, podem-se considerar válidas as análises conduzidas a partir das informações obtidas pela aplicação da regressão.

Com base na constatação de que as informações contábeis sem e com os ajustes da primeira fase do processo de convergências às normas internacionais de contabilidade são relevantes para o mercado de capitais, cabe analisar se a mudança trouxe ganho informacional às demonstrações contábeis, mais especificamente ao lucro líquido e ao patrimônio líquido.

Em uma primeira análise, pode comparar os $\mathrm{R}^{2}$ ajustados das duas regressões (tabelas 1 e 2). Pode perceber que o coeficiente de determinação das informações com as alterações (72,76\%) é ligeiramente superior ao das informações sem as alterações $(69,08 \%)$ previstas pela Lei n. ${ }^{\circ} 11.638 / 07$ e pelos Pronunciamentos do CPC, aplicáveis ao exercício de 2008 em diante. Isso mostra que o poder de explicação do comportamento do preço das ações pelo LLPA e pelo PLPA aumentou. Em outras palavras, as informações divulgadas apenas em 2009 (referentes à reapresentação das demonstrações de 2007) trazem em si mais elementos considerados pelo mercado de capitais. Isso é corroborado pela análise dos CIA e CIS, pois ambos os casos têm-se valores menores para a regressão com as informações alteradas pela legislação. 


\section{repec}

Impacto do Processo de Convergência às Normas Internacionais de Contabilidade na Relevância das Informações Contábeis

\section{CONSIDERAÇÕES FINAIS}

Este estudo procurou investigar o impacto do processo de convergência às normas internacionais de contabilidade no Brasil por meio da análise da relevância das informações contábeis, primordialmente de LL e PL, tendo como base os dados de 2007 sem e com as alterações introduzidas pela Lei n. ${ }^{\circ} 11.638 / 07$ e pelos Pronunciamentos do CPC, aplicáveis ao exercício de 2008 em diante.

Os principais resultados mostram que as informações contábeis de LLPA e PLPA do exercício de 2007, sem e com as alterações da legislação, apresentam-se relevantes para o mercado de capitais. Porém, uma comparação entre as duas regressões utilizadas na análise mostra que houve um ganho informacional para as informações contábeis com as alterações introduzidas pela primeira fase do processo de convergências contábil às normas internacionais.

É importante ressaltar que a Tabela 2, que sintetiza os aspectos alterados pela Lei n. ${ }^{\circ}$ 11.638/07 (BRASIL, 2007) e pelos Pronunciamentos do CPC, aplicáveis ao exercício de 2008 em diante, mostra que praticamente todos os itens têm impacto direto ou indireto no LL e no PL. Com isso, a análise, com apenas essas duas informações, pode ser considerada significativa em um estudo sobre impacto da primeira fase do processo de convergência às normas internacionais de contabilidade sobre a relevância da informação contábil. Logo, conclui-se que tais alterações trouxeram ganho informacional para as demonstrações contábeis em relação à formação dos preços das ações no mercado de capitais.

O ganho do conteúdo informacional das informações contábeis pode estar associado à introdução de novos critérios de mensuração e reconhecimento contábil. Esses novos critérios tendem a deixar a informação contábil mais próxima da realidade econômica da empresa, rompendo o paradigma de que ela representa uma cifra "meramente contábil". Adicionalmente, destaca-se a melhoria no disclosure, tanto em termos quantitativos quanto qualitativos.

Cabe salientar que isso reflete uma situação interessante sobre o ponto de vista do uso da informação contábil pelo mercado de capitais. Essas conclusões apontam para o fato de que o mercado de capitais já estava considerando/refletindo (pois os preços são de 2008) informações ainda não disponíveis contabilmente, pois as novas informações, que são mais relevantes, só foram divulgadas em 2009. Isso traz uma relevância adicional para as mudanças implantadas pelo processo de convergência às normas internacionais de contabilidade, pois os resultados indicam uma situação como se o mercado já fizesse por conta própria ajustes no LL e PL de forma a melhorar essas informações e esses ajustes estivessem relacionados às mudanças preconizadas pela Lei n. ${ }^{\circ}$ 11.638/07 (BRASIL, 2007) e pelos Pronunciamentos do CPC, aplicáveis ao exercício de 2008 em diante.

De maneira geral, os resultados desse estudo corroboram os achados de Bartov, Goldberg e Kim (2005); Hung e Subramanyam (2007); Barth, Landsman e Lang (2008); Chalmers, Clinch e Godfrey (2008); Chalmers, Clinch e Godfrey (2009); Morais e Curto (2009) e Kadri, Aziz e Ibrahim (2009), e contradizem os resultados de Niskaen, Kinnunen e Kasanen (2000) e Morais e Curto (2008), pois se observou que o processo de convergência aos padrões internacionais de contabilidade acrescentou relevância às informações contábeis.

Um fator limitador importante e que não foi controlado por esse estudo é que os resultados podem estar impactados por algum viés oriundo da Teoria da Evidenciação, já que os dados utilizados foram apresentados voluntariamente pelas empresas. Cabe apenas ressaltar que a princípio esse efeito não é observável nas diferenças entre as informações sem e com as alterações, já que no caso de várias empresas observa-se redução do PL e/ou do LL e em várias outras o aumento desses valores.

Cabe salientar, por fim, que estudos dessa natureza devem ser conduzidos, ou seja, é necessário procurar entender e mapear os impactos oriundos do processo de convergência contábil às normas internacionais no Brasil, seja por meio da análise do value relevance ou de qualquer outra perspectiva desse problema. Isso porque é importante para contadores, órgãos reguladores e investidores em geral ter conhecimento se a adoção do IFRS tem efeito sobre a informação disponibilizada pela contabilidade. Além disso, é importante adicionar à literatura que investiga impactos da adoção do IFRS em diferentes contextos, países e culturas, os efeitos dessa adoção no Brasil. 


\section{REFERÊNCIAS}

AMIR, E; HARRIS, T. S; VENUTTI, E. K. A comparison of value relevance of US versus non-US-GAAP accounting measures using Form 20-F reconciliations. Journal of Accounting Research Supplement, v. 31, p. 230-264. 1993

BALL, R. J.; BROWN, W. An empirical evaluation of accounting income numbers. Journal of Accounting Research, v. 6, p. 159-178. 1968

BARTH, M. E.; BEAVER, W. H.; LANDSMAN, W. R. The relevance of the value relevance literature for financial accounting standard setting: another view. Journal of Accounting and Economics, v. 31, p. $77-104.2001$

BARTH, M. E.; LANDSMAN, W. R.; LANG, M. H. International accounting standards and accounting quality. Journal of Accounting Research, v. 46, n. 3, p. 467-498. 2008

BARTOV, E.; GOLDBERG, S. R.; KIM, M. Comparative Value Relevance Among German, U.S., and International Accounting Standards: A German Stock Market Perspective. Journal of Accounting, Auditing \& Finance, v. 20, p. 95-119. 2005

BEAVER, W. The information content of annual earnings announcements. Journal of Accounting Research, v. 6, p. 67-92. 1968

BRAGA, J. P.; ARAÚJO, M. B. V.; MACEDO, M. A. S.; CORRAR, L. J. 2010. Análise do impacto das mudanças nas normas contábeis brasileiras: Um estudo comparativo dos indicadores econômico-financeiros de companhias brasileiras para o ano de 2007. In: SEMINÁRIOS DE ADMINISTRAÇÃO SEMEAd, 13, 2010, São Paulo. Anais.... São Paulo: EAD/FEA/USP, CD-ROM.

BRASIL. Lei n ${ }^{\circ}$ 11.638, de 28 de dezembro de 2007. Altera e revoga dispositivos da Lei no 6.404, de 15 de dezembro de 1976, e da Lei no 6.385, de 7 de dezembro de 1976, e estende às sociedades de grande porte disposições relativas à elaboração e divulgação de demonstrações financeiras.

BRASIL. Lei nº. 6.385/76. Dispõe sobre o mercado de valores mobiliários e cria a Comissão de Valores Mobiliários. Disponível em: http://www.planalto.gov.br/ccivil_03/leis/16385.htm. Acesso em: 13 out 2009.

BRASIL. Lei $\mathbf{n}^{\circ} \mathbf{. 6 . 4 0 4}$, de 15 de dezembro de 1976. Dispõe sobre as Sociedades por Ações.

BRASIL. Medida Provisória ${ }^{\circ}$ 449, de 3 de dezembro de 2008. Altera a legislação tributária federal relativa ao parcelamento ordinário de débitos tributários, concede remissão nos casos em que especifica, institui regime tributário de transição, e dá outras providências.

CFC - CONSELHO FEDERAL DE CONTABILIDADE. Resolução CFC n $\mathbf{n}^{\mathbf{0}} \mathbf{1 0 5 5} / \mathbf{0 5}$. Cria o Comitê de Pronunciamentos Contábeis (CPC), e dá outras providências. Disponível em: http://www.cfc.org.br/ sisweb/sre/Confirmacao.aspx. Acesso em: 13 out 2009.

CPC - COMITÊ DE PRONUNCIAMENTOS CONTÁBEIS. Pronunciamento Técnico CPC 13 - Adoção inicial da Lei 11.638/07 e da Medida Provisória 449/08. Disponível em: < http://www.cpc.org.br>. Acesso em: 13 out 2009. 
CHALMERS, K; CLINCH, G. J.; GODFREY, J. M. Adoption of International Financial Reporting Standards: Impact on the Value Relevance of Intangible Assets. Australian Accounting Review. v. 18, p. $237-247.2008$

CHALMERS, K.; CLINCH, G. J.; GODFREY, J. M.. Changes in Value Relevance of Financial Information Upon IFRS Adoption. 2009. Social Science Research Network (SSRN). Disponível em: <www. ssrn.com>. Acesso em: 18 nov 2010.

COLLINS, D.; MAYDEW, E. L.; WEISS, L. Changes in the value relevance of earnings and book value over the past forty years. Journal of Accounting and Economics, v. 24, p. 39-67. 1997.

CORRAR, L. J.; PAULO, E.; DIAS FILHO, J. M. (Coords.). Análise Multivariada para Cursos de Administração, Ciências Contábeis e Economia. São Paulo: Atlas, 2007.

COSTA, F. M.; LOPES, A. B. Ajustes aos US-GAAP: Estudo empírico sobre sua relevância para empresas brasileiras com ADRs negociadas na Bolsa de Nova Iorque. Revista de Contabilidade \& Finanças. Edição 30 Anos de Doutorado, p. 45-57. 2007.

DHALIWAL, D; SUBRAMANYAM, K. R; TREZEVANT, R. Is comprehensive income superior to net income as a measure of firm performance? Journal of Accounting and Economics, v. 26, p. 43-67. 1999.

FÁVERO, L. P.; BELFIORE, P.; SILVA, F. L. da; CHAN, B. L. Análise de dados - modelagem multivariada para tomada de decisões. Rio de Janeiro: Campus/Elsevier, 2009.

GUJARATI, D. Econometria Básica. Rio de Janeiro: Campus/Elsevier, 2006.

HARRIS, T. S., LANG, M., MOLLER, H. P. The value relevance of German accounting measures: An empirical analysis. Journal of Accounting Research, v. 32, p. 187-209, 1994.

HOLTHAUSEN, R. W.; WATTS, R. L. The relevance of the value-relevance literature for financial accounting standard setting. Journal of Accounting and Economics, v. 31, p. 3-75. 2001.

HUNG, M.; SUBRAMANYAM, K. R. Financial statement effects of adopting international accounting standards: the case of Germany. Review of Accounting Studies, v. 12, p. 623-657, 2007.

IUDÍCIBUS, S.; MARTINS, E.; GELBCKE, E. R. 2009. Manual de contabilidade das sociedades por ações: (Aplicável às demais sociedades) - Suplemento. 2. ed. São Paulo: Atlas.

KADRI, M. H.; AZIZ, R. A.; IBRAHIM, M. K. Value relevance of book value and earnings: evidence from two different financial reporting regimes. Journal of Financial Reporting \& Accounting, v. 7, n. 1, p. 1-16. 2009.

KOTHARI, S. P. Capital Markets Research in Accounting. Journal of Accounting and Economics, v. 31, p. 105-231. 2001.

LOPES, A. B. A relevância da informação contábil para o mercado de capitais: o Modelo de Ohlson aplicado à Bovespa. São Paulo, SP. Tese (Doutorado em Controladoria e Contabilidade) - Faculdade de Economia, Administração e Contabilidade, USP. 2001. 
MARTINS, G. A.; THEÓPHILO, C. R. Metodologia da Investigação Científica para Ciências Sociais Aplicadas. 2 ed. São Paulo: Atlas. 2009.

MORAIS, A. I.; CURTO, J. D. Accounting quality and the adoption of IASB Standards - portuguese evidence. Revista Contabilidade \& Finanças, v. 19, n. 48, p. 103-111. 2008.

MORAIS, A. I.; CURTO, J. D. Mandatory adoption of IASB Standards: value relevance and countryspecific factors. Australian Accounting Review, v. 19, n. 49, p. 128-143. 2009.

NISKANEN, J.; KINNUNEN, J.; KASANEN, E. The value relevance of IAS reconciliation components: empirical evidence from Finland. Journal of Accounting and Public Policy, v. 19, p. 119-137. 2000.

VERGARA, S. C. Projetos e Relatórios de Pesquisa em Administração. 10. ed. São Paulo: Atlas. 2009. 